\title{
Yaşlılarda kandida özofajiti: Tek merkez deneyimi
}

\author{
Candida esophagitis in elderly patients: A single center experience
}

\author{
(D) Ferit ÇELIK ${ }^{1}$, D Alper UYSAL ${ }^{1}$, (DAli ŞENKAYA ${ }^{1}$, (D) Nalan Gülşen ÜNAL ${ }^{1}$, (D) lilkçe Akgün KURTULMUŞ², \\ (D) Fatih TEKIN' ${ }^{1}$, (DAhmet Ömer ÖZÜTEMIZ1
}

Ege Üniversitesi Tıp Fakültesi ${ }^{1}$ Gastaroenteroloji Bilim Dalı, ${ }^{2}$ ç̧ Hastalıkları Anabilim Dalı, İzmir

\begin{abstract}
Giriş ve Amaç: Kandida özofajiti, özofagus mukozasının fungal enfeksiyonudur. Bu çalışmada amaç; insan immün yetmezlik virüsü negatif yaşıllarda kandida özofajiti ile ilişkili olarak predispozan faktörleri belirlemek ve eşlik eden endoskopi bulgularını sunmaktır. Gereç ve Yöntem: Bu çalışma; herhangi bir nedenle endoskopi yapılıp, kandida özofajiti tanısı koyulan, insan immün yetmezlik virüsü (-), $\geq 65$ yaş hastaların retrospektif tek merkezli irdelenmesini içermektedir. Hastaların yaş, cinsiyet, esslik eden hastalıkları, insan immün yetmezlik virüsü enfeksiyonu varlığı, kullandığı ilaçları, Diabetes Mellitus varlığı, proton pompa inhibitörü kullanımı, örneklemenin nasıl yapıldığı, başvuru semptomları ve endoskopi yapılma nedenleri taranmıştır. Bulgular: Bu çalışmada 65 yaş üstü olup endoskopi yapılan toplam 2462 hastanın 16'sında (\%0.65) kandida özofajiti saptanmıştır. Kandida özofajiti saptanan hastaların yaşları 65 ile 88 arasında olup yaş ortalaması $76.75 \pm 7.9$ yıldır. Hastaların 8'i (\%50) kadındır. Hastaların en sık semptom ve endoskopi yapılma nedeni 8 (\%50) hastada disfajidir. Hastaların 5'inde (\%31.3) Diabetes Mellitus tanısı saptanmıştır. Hastaların ilaç kullanımları incelendiğinde; $\sigma^{\prime}$ sının (\%37.5) sürekli proton pompa inhibitörü kullandığı, 5'inin (\%31.3) son 1 ay içerisinde antibiyotik kullanım öyküsü olduğu anlaşılmıştır. On dört hastadan (\%87.5) biyopsi forsepsi ile, 2 hastadan (\%12.5) ise firçalama tekniği ile örnek alınarak tanıya gidilmiştir. Sonuç: Bu çalışma, bildiğimiz kadarıla ülkemizde geriatrik popülasyonda kandida özofajiti ile ilişkili ilk çalısmadır. Çalışmamızda insan immün yetmezlik virüsü (-), kandida özofajiti olan geriatrik hastaların yaş etkeni yanında kullanılan ilaçların ve komorbiditelerin de risk faktörü olduğu, bu hastalarda semptomların değişkenlik gösterebildiği akılda tutulmalıdır.
\end{abstract}

Anahtar kelimeler: Kandida, özofajit, endoskopi, risk faktörleri
Background and Aims: Candida esophagitis is a fungal infection of the esophageal mucosa. This study aimed to determine the predisposing factors and accompanying endoscopy findings associated with Candida esophagitis in human immunodeficiency virus-negative elderly patients. Materials and Methods: This was a retrospective single center study involving human immunodeficiency virus-negative patients aged $\geq 65$ years old who underwent endoscopy for any reason and were diagnosed with Candida esophagitis. The age, sex, accompanying diseases, presence of human immunodeficiency virus infection, drugs used, presence of Diabetes Mellitus, use of proton pump inhibitor, how the sampling was done, symptoms at presentation, and the reason for performing endoscopy were reviewed. Results: Candida esophagitis was found in $16(0.65 \%)$ out of 2462 patients aged over 65 years who underwent endoscopy. The patients with Candida esophagitis were aged between 65 and 88 years, with an average age of $76.75 \pm 7.9$ years. Eight (50\%) of the patients were female. Dysphagia was the most common symptom and reason for endoscopy in eight (50\%) patients. Diabetes Mellitus was diagnosed in five $(31.3 \%)$ of the patients. When the drug use of the patients was examined, it was reported that six $(37.5 \%)$ patients were using proton pump inhibitor continuously, and five (31.3\%) patients had a history of antibiotic use in the last one month. The diagnosis was made using biopsy forceps in 14 (87.5\%) patients and the brushing technique in two (12.5\%) patients. Conclusion: To our knowledge, this is the first study investigating Candida esophagitis in the geriatric population in our country. We suggest that drug use and comorbidities, as well as age factor, were risk factors for Candida esophagitis in geriatric human immunodeficiency virus -negative patients, and symptoms may vary in these patients.

Key words: Candida, esophagitis, endoscopy, risk factors

\section{GíRiş}

Kandida özofajiti (KÖ), özofagus mukozasının fungal enfeksiyonudur. Endoskopinin yaygınlaşması ile birlikte hastalığın tanısında artış olmuştur (1). En sık etken Candida albicans'dır (2). KÖ'li hastalar asemptomatik olabilir, ancak olgular en sık disfaji, odinofaji ve retrosternal ağrı ile başvurmaktadırlar (3-5).

Genel olarak hastalığın oluşumu için bir predispozan faktör gereklidir. Proton pompa inhibitörü (PPI) kullanımı,

\footnotetext{
İletişim: Ferit ÇELIK

Ege Üniversitesi Tıp Fakültesi, Gastroenteroloji Bilim Dalı,

35100, Bornova/Izmir

E-mail: drferitcelik35@yahoo.com.tr
}

histamin-2 reseptör antagonistleri kullanımı, inhale ve sistemik kortikosteroid kullanımı, antibiyotik kullanımı, immünsupresif ajan kullanımı, geçirilmiş vagotomi, mekanik veya fonksiyonel bir özofagus hastalığı varlığı, Diabetes Mellitus (DM), hipotiroidizm, hipoparatiroidizm, hipoadrenokortisizm varlığı, insan immün yetmezlik virüsü (HIV) pozitif olmak, kemoterapi alıyor olmak, boyun bölgesine radyasyon uygulaması, kronik alkol kullanımı, yetersiz beslenme ve ileri yaş predispozan faktörlerdir (3,4,6-11).

Çelik F, Uysal A, Şenkaya A, et al. Candida esophagitis in elderly patients: A single center experience. The Turkish Journal of Academic Gastroenterology 2021;20:70-74. DOI: 10.17941/agd.978470

Geliş Tarihi: 26.03.2021 • Kabul Tarihi: 08.05.2021 
Tanı, üst gastrointestinal sistem endoskopisinde özofagus mukozasının değişik kısımlarında yıkamakla geçmeyen, beyaz mukozal plakların görülmesi ve bu eksudadif plaklardan fırçalama yöntemi veya biyopsi forsepsi ile alınan doku ile koyulur $(3,4)$. Ülkemizde HIV (-) yaşılıarda KÖ ile ilgili çalışma bulunmamaktadır. Bu çalışmada amaç; HIV (-) yaşılıarda KÖ ile ilişkili olarak predispozan fakörleri belirlemek ve eşlik eden endoskopi bulgularını sunmaktır.

\section{GEREÇ ve YÖNTEM}

Bu çalışma; Ocak 2018- Mart 2020 tarihleri arasında hastanemiz gastroenteroloji bilim dalında herhangi bir nedenle endoskopi yapılıp, KÖ tanısı koyulan, HIV (-), 65 yaş ve üstü hastaların retrospektif tek merkezli irdelenmesini içermektedir. Hastalar, klinikte kullanılan Endocam sistemine 'kandida özofajiti' yazılarak taranmış ve endoskopi raporlarına ulaşılmıştır. Üst endoskopi raporlarından eşlik eden endoskopi bulgularına, örneklemenin nasıl yapıldığına, başvuru semptomu ve endoskopi yapılma nedenine ulaşılmıştır. Ayrıca hastane elektronik veri tabanı kullanılarak hastaların; yaş, cinsiyet, eşlik eden hastalıkları, HIV enfeksiyonu varlığı, kullandığı ilaçları, DM varlığı, PPI kullanımı olgu rapor formuna kaydedilmiştir. 65 yaş altı, verilerine tam ulaşılamayan, HIV (+) veya HIV serolojisi bulunmayan hastalar çalışma dışı bırakılmıştır. Dünya Sağlık Örgütü'nün tanımladığı üzere yaş gruplarına göre 65-75 yaş arası "erken yaşlı", 75-85 yaş arası "orta yaşı"ı", 85 ve üzeri "ileri yaşı" olarak tanımlanmışırı (12).

Endoskopik incelemeler, Olympus GIF-HQ190 cihazı ile bir gastroenteroloji uzmanı veya onun nezaretinde gastroenteroloji yan dal asistanı tarafından, endoskopi hemşiresi eşliğinde yapılmıştır. KÖ tanısı, endoskopi esnasında özofagus mukozasının değişik kısımlarında yıkamakla geçmeyen, beyaz mukozal plakların görülmesi (atılmış pamuk manzarası) ve bu plaklardan fırçalama tekniği ile veya biyopsi forsepsi ile alınan örneklerde maya veya psödohif görülmesi ile koyulmuştur. Resim 1'de KÖ'lü olgularımızın endoskopik görüntüleri verilmiştir. Çalışma

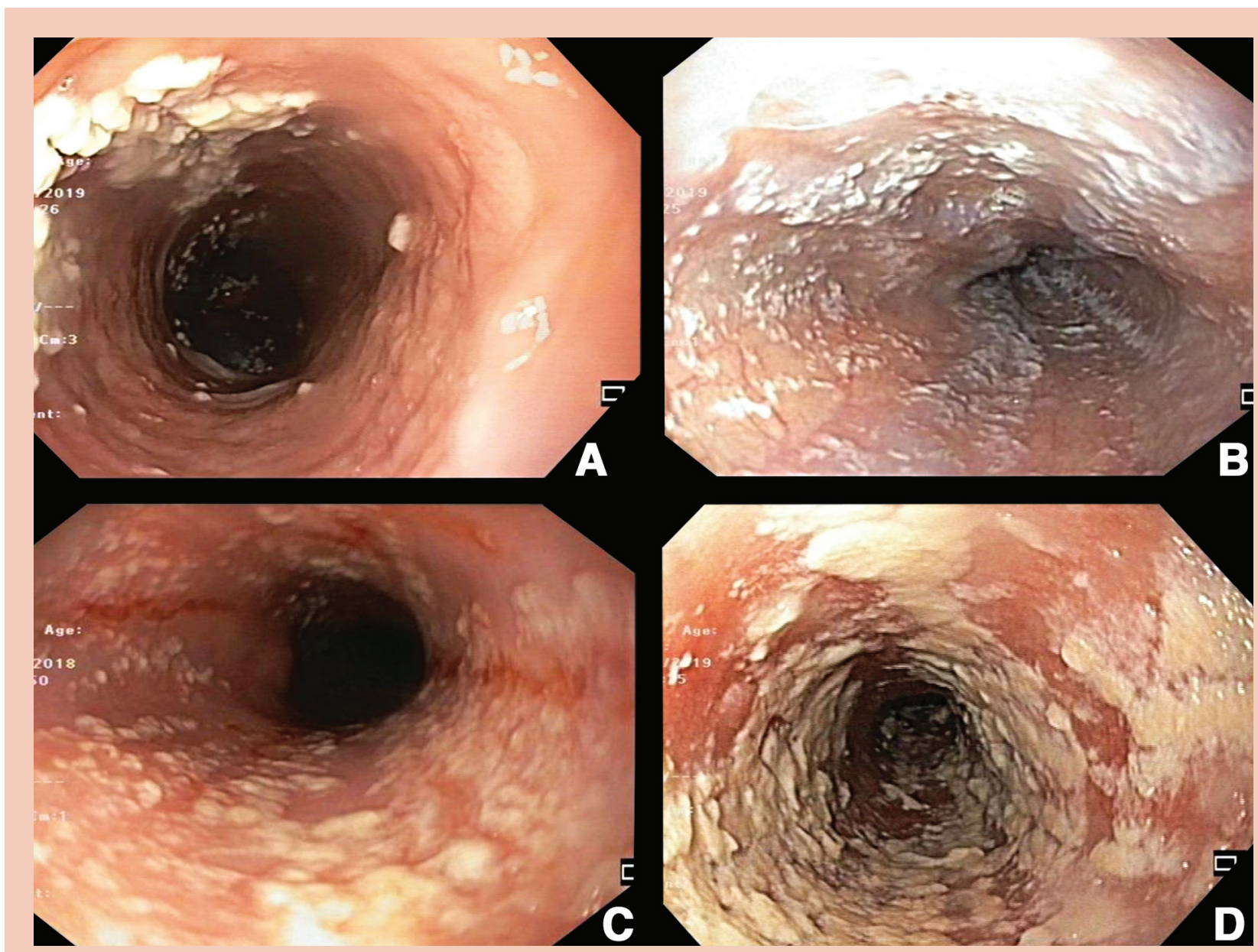

Resim 1 A-D. Hastalarımızın üst endoskopik bulgularına ait örnekler. Özofagusta beyaz renkli, yıkamakla geçmeyen, eksudatif plaklar ile karakterize atılmış pamuk manzarası görülmektedir. 
için Ege Üniversitesi Tıp Fakültesi, Tıbbi Araştırmalar Etik Kurulu'ndan 09.09.2020 tarih ve 20-9T/21 sayı ile yerel etik kurul onayı alınmıştır.

Tablo 1. Hastaların demografik özellikleri, başvuru nedenleri, komorbiditeleri ve örnekleme yöntemi

\begin{tabular}{|c|c|}
\hline & n (\%) \\
\hline \multicolumn{2}{|l|}{ Yaş } \\
\hline $65-75$ arası & $7(43)$ \\
\hline $75-85$ arası & $6(37)$ \\
\hline 85 ve üstü & $3(20)$ \\
\hline \multicolumn{2}{|l|}{ Cinsiyet } \\
\hline Erkek & $8(50)$ \\
\hline Kadın & $8(50)$ \\
\hline \multicolumn{2}{|c|}{ Semptom/Endoskopi endikasyonu } \\
\hline Disfaji & $8(50)$ \\
\hline Asemptomatik* & $4(25)$ \\
\hline Dispepsi & $2(12,5)$ \\
\hline Hematemez & $1(6,3)$ \\
\hline Pirozis -regürjitasyon & $1(6,3)$ \\
\hline \multicolumn{2}{|l|}{ Antibiyotik Kullanımı } \\
\hline Var & $11(68,8)$ \\
\hline Yok & $5(31,2)$ \\
\hline \multicolumn{2}{|l|}{ ASA Kullanımı } \\
\hline Var & $4(25)$ \\
\hline Yok & $12(75)$ \\
\hline \multicolumn{2}{|l|}{ PPI Kullanımı } \\
\hline Var & $10(62,5)$ \\
\hline Yok & $6(37.5)$ \\
\hline \multicolumn{2}{|l|}{ Kullandığı ilaç } \\
\hline İnhale kortikosteroid & $3(18,8)$ \\
\hline Kematerapötik & $3(18,8)$ \\
\hline İnsülin & $3(18,8)$ \\
\hline İmmünsupresif & $1(6.2)$ \\
\hline Diğerleri** & $6(37.4)$ \\
\hline \multicolumn{2}{|l|}{ Komorbidite } \\
\hline DM & $5(31,3)$ \\
\hline HT & $4(25)$ \\
\hline $\mathrm{KAH}$ & $3(18,8)$ \\
\hline $\mathrm{KOAH}$ & $2(12,5)$ \\
\hline \multicolumn{2}{|l|}{ Örnekleme } \\
\hline Biyopsi forsepsi & $14(87,5)$ \\
\hline Fırça & $2(12,5)$ \\
\hline
\end{tabular}

*Demir eksikliği anemisi (n: 2), intestinal metaplazi ve atrofik gastrit takip (n: 1), toraks tomografisinde özofagusta duvar kalınlık artışı (n: 1).

**Antidepresan, antihipertansif, oral antidiabetik, antitiroid, bifosfonat, ursodeoksikolik asit.

ASA: Asetil salisilik asit, PPI: Proton pompa inhibitörü, DM: Diabetes mellitus, HT: Hipertansiyon, KAH: Koroner arter hastalığı, KOAH: Kronik obstrüktif akciğer hastalığı.
İstatistiksel analizlerde; SPSS Statistics Ver. 22.0 (SPSS Inc. Chicago, IL.USA) programı kullanılmışır. Değişkenlerin normal dağılıma uygunluğu görsel (histogram) ve analitik yöntemlerle (Shapirov Wilk testi) incelenmiştir. Çalışmada toplanmış olan verilerden sayısal olanlar ortalama, ortanca, standart sapma, en büyük ve en küçük değer; kategorik veriler ise oran, yüzde gibi tanımlayıcı yöntemlerle ifade edilmiştir.

\section{BULGULAR}

Bu çalışmada 65 yaş üstü olup üst endoskopi yapılan toplam 2462 hastanın 16'sında (\%0.65) KÖ saptanmıştır. KÖ saptanan hastaların yaşları 65 ile 88 arasında olup yaş ortalaması $76.75 \pm 7.9$ yıldır. Yedi (\%43.8) hastanın erken yaşı, 6 (\%37.5) hastanın orta yaşlı ve $3(\% 18.7)$ hastanın ileri yaşlı olduğu saptanmıştır. Hastaların 8'i (\%50) kadındır.

Hastaların en sık semptomu ve endoskopi yapılma nedeni disfajidir [8 (\%50) hasta]. Disfajiyi takiben sırasılyla 2 (\%12.5) olguda dispepsi, 1 (\%6.3) olguda hematemez ve 1 (\%6.3) olguda pirozis-regürjitasyon mevcuttu. Dört (\%25) hastamız asemptomatik olup, bu hastaların 2'sine demir eksikliği anemisi, 1 'ine atrofik gastrit ve intestinal metaplazi takip, 1'ine ise çekilen toraks tomografisinde özofagusta duvar kalınlık artışı saptanması nedeniyle üst endoskopi yapılmış olup KÖ saptanmıştır.

Hastaların komorbiditeleri tek tek incelendiğinde 5 (\%31.3) olguda DM, 4 (\%25) olguda hipertansiyon, 3'ünde (\%18.8) koroner arter hastalı̆ı, 2'sinde (\%12.5) kronik obstrüktif akciğer hastalığı saptanmıştır. Hastaların ilaç kullanımları incelendiğinde 6'sının (\%37.5) sürekli PPI kullandığı, 5'inin (\%31.3) son 1 ay içerisinde antibiyotik kullanım öyküsü olduğu anlaşılmışıı. Hastaların almış olduğu diğer tedavilere bakıldığında 1 (\%6.2) hastanın karaciğer nakli nedeniyle immünsupresif tedavi gördüğü, üç (\%18.8) hastamızın kemoterapi aldığı ve 3 (\%18.8) hastamızın da inhale steroid kullandığı saptanmıştır. Hastaların demografik özellikleri, başvuru nedenleri, komorbiditeleri ve örnekleme yöntemi Tablo 1'de gösterilmiştir.

Tüm olguların endoskopileri incelendiğinde KÖ dışında 4 (\%25) hastada herhangi bir bulguya saptanmadı. Hastaların 2'sinde (\%12.5) hiatus hernisi, 2'sinde (\%12.5) atrofik gastrit ve intestinal metaplazi, 2'sinde (\%12.5) midede polip, 1'er (\%6.2) olguda ise mide ülseri, enterogastrik reflü gastropatisi, bulbit, barrett özofagus, özofagusta benign darlık ve özofagusta varis ile konjestif gastropati saptanmıştır. On dört (\%87.5) hastadan biyopsi forsepsi ile, 2 (\%12.5) hastadan ise fırçalama tekniği ile örnek alınarak tanıya gidilmiş̧ir. Hastalarımızın olgu bazında tüm demografik, klinik ve endoskopik özellikleri detaylı olarak Tablo 2'de gösterilmiştir. 


\begin{tabular}{|c|c|c|c|c|c|c|c|c|c|c|}
\hline Olgu & Yaş & Cinsiyet & $\begin{array}{l}\text { Endoskopi } \\
\text { Endikasyonu }\end{array}$ & $\begin{array}{c}\text { Antibiyotik } \\
\text { Kullanımı }\end{array}$ & DM & $\begin{array}{l}\text { Kullandığı } \\
\text { ilaçlar }\end{array}$ & $\begin{array}{l}\text { Bilinen } \\
\text { Hastalık }\end{array}$ & $\begin{array}{c}\text { PPI } \\
\text { Kullanımı }\end{array}$ & $\begin{array}{c}\text { Eşlik Eden } \\
\text { Endoskopi } \\
\text { Bulgusu }\end{array}$ & $\begin{array}{c}\text { Örnek } \\
\text { Alınma } \\
\text { Şekli }\end{array}$ \\
\hline 1 & 70 & Erkek & Dispepsi & Yok & Yok & Immünsupresif & KC nakli & Var & Ülser & $\begin{array}{l}\text { Biyopsi } \\
\text { forsepsi }\end{array}$ \\
\hline 2 & 88 & Kadın & Disfaji & Yok & Yok & Kemoterapi & KLL & Yok & $\begin{array}{l}\text { Hiatus } \\
\text { hernisi }\end{array}$ & $\begin{array}{l}\text { Biyopsi } \\
\text { forsepsi }\end{array}$ \\
\hline 3 & 78 & Kadın & Dispepsi & Yok & Yok & Antidepresan & Psikoz & Yok & $\begin{array}{l}\text { Enterogastrik } \\
\text { reflü }\end{array}$ & $\begin{array}{l}\text { Biyopsi } \\
\text { forsepsi }\end{array}$ \\
\hline 4 & 87 & Kadın & Disfaji & Var & Yok & Kemoterapi & KML & Var & $\begin{array}{l}\text { Bulgu } \\
\text { yok }\end{array}$ & $\begin{array}{l}\text { Biyopsi } \\
\text { forsepsi }\end{array}$ \\
\hline 5 & 81 & Kadın & Disfaji & Yok & Yok & UDKA & $\begin{array}{l}\text { Primer Biliyer } \\
\text { Kolanjit }\end{array}$ & Var & Bulgu yok & $\begin{array}{l}\text { Biyopsi } \\
\text { forsepsi }\end{array}$ \\
\hline 6 & 69 & Erkek & $\begin{array}{l}\text { Toraks BT: } \\
\text { özofagus duvar } \\
\text { kalınlık artışı }\end{array}$ & Var & Var & $\begin{array}{l}\text { Inhaler } \\
\text { Steroid }\end{array}$ & $\mathrm{IPF}+\mathrm{DM}$ & Yok & Bulbit & $\begin{array}{l}\text { Biyopsi } \\
\text { forsepsi }\end{array}$ \\
\hline 7 & 66 & Erkek & Disfaji & Yok & Yok & ASA & $\mathrm{KAH}$ & Var & $\begin{array}{l}\text { Hiatus } \\
\text { hernisi }\end{array}$ & $\begin{array}{l}\text { Biyopsi } \\
\text { forsepsi }\end{array}$ \\
\hline 8 & 80 & Erkek & Hematemez & Yok & Var & $A S A+O A D$ & $K A H+D M+K B Y$ & Var & Polip & $\begin{array}{l}\text { Biyopsi } \\
\text { forsepsi }\end{array}$ \\
\hline 9 & 72 & Erkek & $\begin{array}{l}\text { Pirozis/ } \\
\text { Regürjitasyon }\end{array}$ & Yok & Yok & $\begin{array}{c}\text { Inhaler steroid + } \\
\text { Anti-HT }\end{array}$ & $\mathrm{KOAH}+\mathrm{HT}$ & Yok & $\begin{array}{l}\text { Barrett } \\
\text { özofagus }\end{array}$ & Firça \\
\hline 10 & 84 & Kadın & Disfaji & Yok & Var & ASA + Insülin & $\mathrm{DM}+\mathrm{KAH}$ & Yok & $\begin{array}{c}\text { Özofagus } \\
\text { benign darlığı }\end{array}$ & $\begin{array}{l}\text { Biyopsi } \\
\text { forsepsi }\end{array}$ \\
\hline 11 & 87 & Erkek & Disfaji & Var & Var & İnsülin + Antitroid & Tirotoksikozis + DM & Yok & Bulgu yok & $\begin{array}{l}\text { Biyopsi } \\
\text { forsepsi }\end{array}$ \\
\hline 12 & 65 & Kadın & Disfaji & Yok & Yok & Kemoterapi + RT & Özofagus kanseri & Yok & Bulgu yok & $\begin{array}{l}\text { Biyopsi } \\
\text { forsepsi }\end{array}$ \\
\hline 13 & 72 & Erkek & Disfaji & Yok & Yok & Anti-HT & HT + Siroz & Yok & $\begin{array}{c}\text { Varis + Konjestif } \\
\text { gastropati }\end{array}$ & Firça \\
\hline 14 & 69 & Erkek & DEA & Yok & Var & ASA + Insülin + Anti-HT & $H T+D M+K A H$ & Var & Polip & $\begin{array}{l}\text { Biyopsi } \\
\text { forsepsi }\end{array}$ \\
\hline 15 & 84 & Kadın & $\begin{array}{l}\mathrm{iM}+\text { Atrofik } \\
\text { gastrit takip }\end{array}$ & Var & Yok & Inhaler steroid & $\mathrm{KOAH}$ & Yok & $\begin{array}{l}\mathrm{i} M+\text { Atrofik } \\
\text { gastrit }\end{array}$ & $\begin{array}{l}\text { Biyopsi } \\
\text { forsepsi }\end{array}$ \\
\hline 16 & 76 & Kadın & DEA & Yok & Yok & Anti-HT + Bifosfanat & HT + osteoporoz & Yok & $\begin{array}{c}\mathrm{iM}+\text { Atrofik } \\
\text { gastrit }\end{array}$ & $\begin{array}{l}\text { Biyopsi } \\
\text { forsepsi }\end{array}$ \\
\hline
\end{tabular}

PPI: Proton pompası inhibitörü, KC: Karaciğer, ASA: Asetil salisilik asit, OAD: Oral antidiyabetik, HT: Hipertansiyon, Anti-HT: Antihipertansif, RT: Radyoterapi, KLL: Kronik lenfositer lösemi, KML: Kronik myelositer lösemi, UDKA: Ursodeoksikolik asit, IPF: Interstisiyel pulmoner fibrozis, KAH: Koroner arter hastalığı, DM: Diabetes Mellitus, KBY: Kronik böbrek yetmezliği, KOAH: Kronik obstrüktif akciğer hastalığı, DEA: Demir eksikliği anemisi, IM: Intestinal metaplazi, BT: Bilgisayarlı tomografi.

\section{TARTIŞMA}

Candida türleri, mantar özofajitinin en yaygın etkenleridir. Genel popülasyonda KÖ sıklığı \%0.5-10.7 arasında bildirilmiştir (13-16). Çalışmamızda KÖ sıklığı \%0.65 olarak saptanmıştır. Literatürde geniş prevalans aralığı bildirilmekle beraber çalışmamızda KÖ sıklığı beklenin altında görülmüştür. Merkezimizde KÖ sıklığının bu şekilde düşük çıkmasının muhtemel nedeni endoskopik olarak KÖ görünümü olan ancak doku örneklemesi olmayan hastaların çalışma dışı bırakılması olabilir.
İleri yaş, KÖ için risk faktörü olarak tanımlanmıştır (1). Yaşla birlikte KÖ'nin artması beklenirken çalışmamızda geriatrik popülasyonun erken yaşlılık döneminde daha sık görülmüştür. Hastalığın erken yaşlı aralığında daha sık saptanmasının nedeni bu yaş grubunun gastroenteroloji kliniklerine ulaşımının daha kolay olması olabilir. Ülkemizde yapılan bir çalışmada KÖ saptanan hastaların \%54.5'i erkek cinsiyet oluşturmuştur (17). Çalışmamızda da benzer şekilde cinsiyet bakımından farklılık izlenmemiştir. 
Literatürde hastaların en sık başvuru şikayetleri çeşitlilik göstermektedir. Olgular asemptomatik olabileceği gibi, ülkemizde ve dünyada yapılan bir kaç çalışmada epigastrik ağrı en sık başvuru şikayeti olarak rapor edilmiş̧ir $(17,18)$. Underwood ve ark.larının yaptığı çalışmada ise disfaji, odinofaji ve göğüs ağrısı en sık semptom olarak saptanmıştır (19). Çalışmamızda da benzer şekilde en sık başvuru şikayetinin disfaji olduğu görülmüştür.

KÖ'nün gelişiminde, özofagusa kandida kolonizasyonu en önemli nedendir. Bu kolonizasyon normal koşullarda, konakçının tükürük salgılaması ile özofagus lümen içeriğinin temizlenmesi ve sağlam bir mukozal bariyerin varlığı ile engellenmektedir. Sıklıkla bağışıklık sistemi baskılanmış bireylerde KÖ izlenmektedir (19). Literatürde mide asidi baskılanması, antibiyotik kullanımı, vagotomi operasyonu, fonksiyonel ve mekanik özofagus bozuklukları, DM varlığı, hipotiroidizm ve hipoparatiroidizm gibi endokrin hastalıklar rapor edilmiştir $(20,21)$. Muhtemel nedenler olarak, bu hastalıkların özofagusta motilite kusuru yapmaları ve sistemik hastalıkların immün sistemi baskılamaları olarak yorumlanmaktadır (22). Bizim çalışmamızda

\section{KAYNAKLAR}

1. Wilcox CM, Karowe MW. Esophageal infections: etiology, diagnosis and management. Gastroenterologist 1994;2:188-206.

2. Darouiche RO. Oropharyngeal and esophageal candidiasis in immunocompromised patients: treatment issues. Clin Infect Dis. 1998;26:259-72.

3. Rosolowski M, Kierzkiewicz M. Etiology, diagnosis and treatment of infectious esophagitis. Prz Gastroenterol 2013;8:333-7.

4. Alsomali MI, Arnold MA, Frankel WL, et al. Challengesto "Classic" esophageal candidiasis: Looks are usually deceiving. Am J Clin Pathol 2017;147:33-42.

5. Mimidis K, Papadopoulos $\vee$, Margaritis $\vee$, et al. Predisposing factors and clinical symptoms in HIV-negative patients with Candida oesophagitis: are they always present? Int J Clin Pract 2005;59:210-3.

6. Karmeli Y, Stalnikowitz R, Eliakim R, Rahav G. Conventional dose of omeprazole alters gastric flora. Dig Dis Sci 1995;40:2070-3.

7. Baehr PH, McDonald GB. Esophageal infections: risk factors, presentation, diagnosis, and treatment. Gastroenterology 1994;106:50932.

8. Simon MR, Houser WL, Smith KA, Long PM. Esophageal candidiasis as a complication of inhaled corticosteroids. Ann Allergy Asthma Immunol 1997;79:333-8.

9. Andersen L, Frederiksen H, Appleyard M. Prevalence of esophageal Candida colonization in a Danish population: special reference to esophageal symptoms, benign esophageal disorders, and pulmonary disease. J Infect Dis 1992;165:389-92.

10. Takahashi Y, Nagata N, Shimbo T, et al. Long-term trends in esophageal Candidiasis prevalence and associated risk factors with or without HIV infection: Lessons from an endoscopic study of 80,219 patients. PLoS One 2015;10:e0133589.

11. Choi JH, Lee CG, Lim YJ, et al. Prevalence and risk factors of esophageal candidiasis in healthy individuals: a single center experience in Korea. Yonsei Med J 2013;54:160-5. da benzer şekilde DM en sık komorbidite olarak görülmüş olup bunu hipertansiyon ve KOAH izlemiştir. PPI ve histamin-2 reseptör antagonistlerinin kullanımı da KÖ ile ilişkilendirilmiştir. Bunun muhtemel nedeninin daha az asidik bir ortamda yutulan oral mikrofloranın özofagusta kalma şansının artması olduğu düşünülmektedir (6). Çalışmamızda da en sık kullanılan ilaç grubunun PPI'lar olduğu görülmüştür. Bunun ise muhtemel nedeni hasta popülasyonumuzun ileri yaşta olmalarıdır.

Çalışmamızın kısıtlayıcı yönleri olarak; çalışmanın retrospektif olması ve hastaların 65 yaş üstü olarak seçilmesinden dolayı genel prevalans verilememesidir. Sonuç olarak; çalışmamızda HIV (-) KÖ tanısı olan geriatrik hastaların yaş etkeni yanında kullanılan ilaçların ve komorbiditelerin de risk faktörü olduğu, bu hastalarda semptomların değişkenlik gösterebildiği akılda tutulmalıdır.

Etik Kurul: Bu çalışma için Ege Üniversitesi Tıp Fakültesi, Tıbbi Araştırmalar Etik Kurulu'ndan 09.09.2020 tarih ve 20-9T/21 sayı ile yerel etik kurul onayı alınmıştır.

Çıkar Çatışması: Tüm yazarlar herhangi bir çıkar çatışması olmadığını kabul ederler.

12. Beğer T, Yavuzer H. Yaşlılık ve yaşlılık epidemiyolojisi. Klinik Gelişim 2012;25:1-3.

13. Arendrup MC. Epidemiology of invasive candidiasis. Curr Opin Crit Care 2010;16:445-52

14. Jarvis WR. Epidemiology of nosocomial fungal infections, with emphasis on Candida species. Clin Infect Dis 1995;20:1526-30.

15. Hoversten P, Otaki F, Katzka DA. Course of esophageal Candidiasis and outcomes of patients at a single center. Clin Gastroenterol Hepatol 2019;17:200-2.

16. Takahashi $Y$, Nagata $N$, Shimbo $T$, et al. Upper gastrointestinal symptoms predictive of Candida esophagitis and erosive esophagitis in HIV and non-HIV patients. An endoscopy-based cross-sectional study of 6011 patients. Medicine (Baltimore) 2015;94:e2138.

17. Akbaş E. Özofagusun fungal enfeksiyonları; tek merkez deneyimi. Endoskopi Gastrointestinal 2019;27:7-11.

18. Mushi MF, Ngeta N, Mirambo MM, Mshana SE. Predictors of esophageal candidiasis among patients attending endoscopy unit in a tertiary hospital, Tanzania: a retrospective cross-sectional study. Afr Health Sci 2018;18:66-71.

19. Underwood JA, Williams JW, Keate RF. Clinical findings and risk factors for Candida esophagitis in outpatients. Dis Esophagus 2003;16:66-69.

20. Hoversten P, Kamboj AK, Katzka DA. Infections of the esophagus: an update on risk factors, diagnosis, and management. Dis Esophagus 2018;31

21. Kliemann DA, Pasqualotto AC, Falavigna $M$, et al. Candida esophagitis: species distribution and risk factors for infection. Rev Inst Med Trop Sao Paulo 2008;50:261-3.

22. Tamura $Y$, Araki A, Chiba $Y$, et al. A case of type 2 diabetes mellitus in an elderly patient with rapid attenuation of insulin secretion that resembled fulminant type $1 \mathrm{DM}$ but with incomplete beta cell damage. Endocr J 2006;53:633-7. 